\title{
Association between obesity and local control of advanced rectal cancer after combined surgery and radiotherapy
}

\author{
Yunseon Choi, MD, PhD'1, Yun-Han Lee, PhD², Sung Kwang Park, PhD1, \\ Heunglae Cho, MD, PhD'1, Ki Jung Ahn, MD, PhD ${ }^{1}$ \\ 'Department of Radiation Oncology, Inje University Busan Paik Hospital, Inje University College of Medicine, Busan; \\ ${ }^{2}$ Department of Molecular Medicine, Keimyung University School of Medicine, Daegu, Korea
}

Purpose: The association between metabolism and cancer has been recently emphasized. This study aimed to find the prognostic significance of obesity in advanced stage rectal cancer patients treated with surgery and radiotherapy (RT).

Materials and Methods: We retrospectively reviewed the medical records of 111 patients who were treated with combined surgery and RT for clinical stage 2-3 (T3 or N+) rectal cancer between 2008 and 2014. The prognostic significance of obesity (body mass index $[\mathrm{BMI}] \geq 25 \mathrm{~kg} / \mathrm{m}^{2}$ ) in local control was evaluated.

Results: The median follow-up was 31.2 months (range, 4.1 to 85.7 months). Twenty-five patients (22.5\%) were classified as obese. Treatment failure occurred in 33 patients (29.7\%), including local failures in 13 patients (11.7\%), regional lymph node failures in 5 , and distant metastases in 24. The 3-year local control, recurrence-free survival, and overall survival rates were $88.7 \%, 73.6 \%$, and $87.7 \%$, respectively. Obesity $(n=25)$ significantly reduced the local control rate $(p=0.045 ; 3$-year local control, $76.2 \%)$, especially in women $(n=37, p=0.021)$. Segregation of local control was best achieved by BMI of $25.6 \mathrm{~kg} / \mathrm{m}^{2}$ as a cutoff value.

Conclusion: Obese rectal cancer patients showed poor local control after combined surgery and RT. More effective local treatment strategies for obese patients are warranted.

Keywords: Obesity, Rectal cancer, Radiotherapy, Local control, Prognosis

\section{Introduction}

The association between cancer and metabolic effects of obesity is receiving increased attention [1-3]. Seyfried et al. [1] previously argued that cancer is a metabolic disease that evokes disturbances in cellular energy metabolism. The alterations in lipid metabolism is related tumorigenesis [4]. Many studies have recently revealed the relationship between obesity and cancer $[5,6]$, including a prospective cohort study by Calle et al. [7] that studied the association between overweight, obesity, and cancer occurrence. Especially, obesity seems to be greatly associated with occurrence and progression of gastrointestinal cancer [7-9]. Interestingly, rectal cancer risk seems to vary with sex, according to previous studies [10-12].

For American Joint Committee for Cancer (AJCC) stage 2-3 rectal cancer patients-especially T3 or clinically nodepositive patients-preoperative or postoperative radiotherapy

Received 22 March 2016, Revised 2 May 2016, Accepted 19 May 2016.

Correspondence: Yunseon Choi, MD, PhD, Department of Radiation Oncology, Inje University Busan Paik Hospital, Inje University College of Medicine, 75 Bokji-ro, Busanjin-gu, Busan 47392, Korea. Tel: +82-51-890-8606, Fax: +82-51-891-1754, E-mail: rtyoon@gmail.com

(c) This is an Open Access article distributed under the terms of the Creative Commons Attribution Non-Commercial License (http://creativecommons.org/ licenses/by-nc/4.0/) which permits unrestricted non-commercial use, distribution, and reproduction in any medium, provided the original work is properly cited.

www.e-roj.org 
(RT) significantly reduces the local failure rate [13]. Rectal cancer patients undergoing total mesorectal excision also showed improved local control (LC) after RT, although this improvement did not translate into a difference in survival [14]. Therefore, RT is considered the current standard therapy in locally advanced rectal cancer, and RT to the pelvis is recommended for rectal cancer patients because it can reduce the probability of local failures after surgical resection of stage 2 or 3 tumors $[13,15]$.

Controversy remains as to whether obesity has a harmful prognostic effect in advanced stage rectal cancer patients [16]. Seishima et al. [16] previously argued that obese patients who underwent surgery showed high disease-free survival rates compared to non-obese patients. However, Park et al. [17] recently reported that obesity was associated with lower pathologic complete response rates in rectal cancer patients after neoadjuvant chemoradiotherapy. In their study, complete response was associated with better disease-free survival. Therefore, we hypothesized that obesity influenced the local treatment outcomes in patients with rectal cancer after surgery and RT. In this study, we aimed to evaluate the prognostic impact of obesity in rectal cancer, especially focusing on locally advanced stage 2-3 rectal cancer patients who underwent multimodal treatment with surgery, $\mathrm{RT}$, and/or chemotherapy. In addition, the influence of diabetes mellitus (DM), which is generally related to body weight, was also evaluated.

\section{Materials and Methods}

We retrospectively reviewed the medical records of 111 patients who were treated for locally advanced rectal cancer in Inje University Busan Paik Hospital between April 2008 and August 2014. All patients who enrolled in this study were treated with radical surgery (low anterior resection or abdominoperineal resection) and perioperative (postoperative or preoperative) RT. Patients who experienced early postoperative surgical complications (i.e., anastomosis site leakage) were excluded from evaluation. In addition, patients who did not receive the full course of RT were excluded. This study was approved by the Institutional Review Board of Inje University Busan Paik Hospital.

The impact of obesity on the treatment outcome was intensively investigated. Although obesity can be evaluated clinically using several measurements including waist circumference, waist-to-hip ratio, and bioelectrical impedance, body mass index (BMI) is the more commonly used indicator for the diagnosis of obesity. BMI is easy to calculate and can be used to quantify the level of obesity. Therefore, we used BMI to evaluate obesity in the present study. Data for body weight and height were obtained from the electronic anesthesia records for the operation. Obesity was defined as a BMI $\geq 25$ $\mathrm{kg} / \mathrm{m}^{2}$ according to Asian BMI classification [18]. Patients were divided into the following 4 groups based on their BMl: underweight (BMI $<18.5 \mathrm{~kg} / \mathrm{m}^{2}$ ), normal weight (BMI 18.5-23 $\mathrm{kg} / \mathrm{m}^{2}$ ), overweight (BMI $\left.23-25 \mathrm{~kg} / \mathrm{m}^{2}\right)$, and obese (BMI $\geq 25$ $\left.\mathrm{kg} / \mathrm{m}^{2}\right)$. None of the patients enrolled in the study had severe obesity (BMI $\geq 30 \mathrm{~kg} / \mathrm{m}^{2}$ ). As obesity is a predisposing factor of DM, the effect of DM on prognosis was also evaluated. To further analyze the effect of obesity on rectal cancer patients, we performed additional subgroup analyses according to patient sex.

Magnetic resonance imaging was used for evaluating the clinical stage of the cancer. For locally advanced rectal cancer, preoperative or postoperative RT was performed to reduce the local failure rate. The daily radiation dose administered was 1.8 Gy. The median total radiation dose was $50.4 \mathrm{~Gy}$ (range, 45 to $59.4 \mathrm{~Gy}$ ). First, external beam RT up to $45 \mathrm{~Gy}$ was administered to the whole pelvic field. Whole pelvic field irradiation was performed with 10-MV photon beams by using a box field technique. For patients who were anticipated to experience local recurrence (those with mesorectal fascia invasion according to preoperative magnetic resonance imaging and/ or a positive/close resection margin on pathologic reports), reduced field irradiation was added after whole pelvic irradiation. Most patients $(n=108,97.3 \%)$ received reduced field irradiation, which was performed with a boost dose of 5.4-14.4 Gy in 3-8 fractions, with a 2-cm margin to tumor or tumor bed. Nearly half of patients $(n=58,52.3 \%)$ treated with preoperative RT. The other patients ( $n=53,47.7 \%$ ) treated with postoperative RT (Table 1).

Chemotherapy treatment mainly consisted of 5 -fluorouracil ( $n=75,67.6 \%$ ) (Table 1). Most patients who underwent preoperative RT were treated with concurrent chemotherapy (48/58, 82.8\%). Patients who underwent postoperative RT received chemotherapy selectively $(27 / 53,50.9 \%)$, according to their relapse risk defined in pathologic reports.

Follow-up imaging using computed tomography was performed between two to four times a year after the treatment. Local failure was defined as anastomosis site failure, characterized by tumor regrowth in the residual rectum. Regional failure was defined as intrapelvic lymph node relapse. Distant failure was defined as extrapelvic recurrence. LC was defined as the time interval from the colonoscopic 
Table 1. Patient characteristics $(n=111)$

\begin{tabular}{|c|c|}
\hline Characteristic & No. $(\%)$ \\
\hline \multicolumn{2}{|l|}{ Age (yr) } \\
\hline$\leq 50$ & $16(14.4)$ \\
\hline$>50$ & 95 (85.6) \\
\hline \multicolumn{2}{|l|}{ Sex } \\
\hline Male & $74(66.7)$ \\
\hline Female & 37 (33.3) \\
\hline \multicolumn{2}{|l|}{ BMI $\left(\mathrm{kg} / \mathrm{m}^{2}\right)$} \\
\hline$<18.5$ & $7(6.3)$ \\
\hline $18.5-23$ & $52(46.8)$ \\
\hline $23-25$ & $27(24.3)$ \\
\hline$\geq 25$ & $25(22.5)$ \\
\hline \multicolumn{2}{|l|}{ Diabetes } \\
\hline Yes & $16(14.4)$ \\
\hline No & 95 (85.6) \\
\hline \multicolumn{2}{|l|}{ CEA (ng/mL) } \\
\hline$<4.7$ & 66 (59.5) \\
\hline$\geq 4.7$ & $45(40.5)$ \\
\hline \multicolumn{2}{|l|}{ Clinical T stage } \\
\hline $\mathrm{T} 2$ & $5(4.5)$ \\
\hline T3 & $106(95.5)$ \\
\hline \multicolumn{2}{|l|}{ Clinical N stage } \\
\hline NO & $32(28.8)$ \\
\hline $\mathrm{N}+$ & 79 (71.2) \\
\hline \multicolumn{2}{|l|}{ Type of surgery } \\
\hline APR & $27(24.3)$ \\
\hline LAR & $84(75.7)$ \\
\hline \multicolumn{2}{|l|}{ Resection margin } \\
\hline Ro & $102(91.9)$ \\
\hline R1-2 & $9(8.1)$ \\
\hline \multicolumn{2}{|l|}{ Type of RT } \\
\hline Preoperative RT & $58(52.3)$ \\
\hline Postoperative RT & $53(47.7)$ \\
\hline \multicolumn{2}{|l|}{ 5-FU chemotherapy } \\
\hline Yes & $75(67.6)$ \\
\hline No & $36(32.4)$ \\
\hline
\end{tabular}

BMI, body mass index; CEA, carcinoembryonic antigen; APR, abdominoperineal resection; $L A R$, lower anterior resection; $R T$, radiotherapy; 5-FU, 5-fluorouracil.

biopsy date to local failure. Recurrence-free survival (RFS) was defined as the time from the colonoscopic biopsy date to overall progression (including local failure, regional failure, and distant metastases). Overall survival (OS) was defined as the time interval from the colonoscopic biopsy date to the date of death or last follow-up. The primary endpoint of this study was LC.

For statistical analysis, SPSS ver. 18.0 (SPSS Inc., Chicago, IL, USA) was used. The Fisher exact test was used to determine the clinical factors related to treatment failure. Actuarial LC and RFS rates were estimated by using the Kaplan-Meier method. The log-rank test was used to compare clinical variables in univariate analysis. We used Cox proportional hazards model to determine the independent prognostic factors of LC. Known prognostic factors for rectal cancer, such as resection margin status and lymph node involvement were included in the multivariate analysis with Cox proportional hazard model. Statistical significance was defined as $p<0.05$ (two-sided test). The maximal chi-square method used to determine which value of BMI best segregated patients into poor- and good-prognosis subgroups (in LC), with the logrank test as the statistics used to measure the strength of the grouping. MaxStat (http://www.maxstat.de/), a maximal chisquare method in R 2.13.0 (R Development Core Team, Vienna, Austria, http://www.R-project.org) was used to identify optimal cutting points.

\section{Results}

Patient characteristics are summarized in Table 1. The median patient age was 61 years (range, 34 to 79 years), and 74 (66.7\%) patients were men. The median BMI was $22.8 \mathrm{~kg} / \mathrm{m}^{2}$ (range, 15.4 to $29.0 \mathrm{~kg} / \mathrm{m}^{2}$ ), and 25 patients (22.5\%) were classified as obese (BMI $\left.\geq 25 \mathrm{~kg} / \mathrm{m}^{2}\right)$. Sixteen patients (14.4\%) were preoperatively diagnosed with type 2 DM. Only one patient with DM received metformin treatment. All patients except 6 patients with mucinous carcinoma were pathologically diagnosed as adenocarcinoma. The median serum carcinoembryonic antigen (CEA) value was $3.83 \mathrm{ng} / \mathrm{mL}$ (range, 0.45 to $115.40 \mathrm{ng} / \mathrm{mL}$ ). Most patients had clinical T3 disease ( $n=106,95.5 \%)$. Seventy-nine patients (71.2\%) had clinically pelvic node-positive disease at preoperative evaluation. Low anterior resection was performed in 84 patients (75.7\%), and abdominoperineal resection was performed in the remaining 27 patients $(24.3 \%)$.

Table 2 shows the comparison of the distribution of clinical factors according to obesity (BMI $\geq 25 \mathrm{~kg} / \mathrm{m}^{2}$ ). No clinical factors showed a significant statistical difference in distribution among either obesity or non-obesity groups.

The median follow-up was 31.2 months (range, 4.1 to 85.7 months). Treatment failure occurred in 33 patients. Local failure occurred in 13 patients (11.7\%) during the followup period. In addition, 5 patients experienced regional lymph node failure, and 24 patients developed distant metastases. Among them, 2 patients experienced both local failure and regional lymph node failure, and 5 patients experienced both local failure and distant metastases. In addition, 4 patients 
Table 2. Comparison of patient characteristics according to obesity (BMI $\geq 25 \mathrm{~kg} / \mathrm{m}^{2}$ )

\begin{tabular}{|c|c|c|c|}
\hline Characteristic & $\mathrm{BMI}<25$ & $\mathrm{BMI} \geq 25$ & $p$-value \\
\hline Age (yr) & & & 0.517 \\
\hline$\leq 50$ & 14 & 2 & \\
\hline$>50$ & 72 & 23 & \\
\hline Sex & & & 0.811 \\
\hline Male & 58 & 16 & \\
\hline Female & 28 & 9 & \\
\hline Diabetes & & & 1 \\
\hline Yes & 13 & 3 & \\
\hline No & 73 & 22 & \\
\hline CEA (ng/mL) & & & 0.171 \\
\hline$<4.7$ & 48 & 18 & \\
\hline$\geq 4.7$ & 38 & 7 & \\
\hline Clinical N stage & & & 0.368 \\
\hline No & 26 & 6 & \\
\hline $\mathrm{N}+$ & 60 & 19 & \\
\hline Type of surgery & & & 0.427 \\
\hline APR & 23 & 4 & \\
\hline LAR & 63 & 21 & \\
\hline Resection margin & & & 1 \\
\hline Ro & 79 & 23 & \\
\hline R1-2 & 7 & 2 & \\
\hline Type of RT & & & 0.372 \\
\hline Preoperative RT & 47 & 11 & \\
\hline Postoperative RT & 39 & 14 & \\
\hline 5-FU chemotherapy & & & 1 \\
\hline Yes & 58 & 17 & \\
\hline No & 28 & 8 & \\
\hline
\end{tabular}

BMI, body mass index; CEA, carcinoembryonic antigen; APR, abdominoperineal resection; $L A R$, lower anterior resection; $R T$, radiotherapy; 5-FU, 5-fluorouracil.

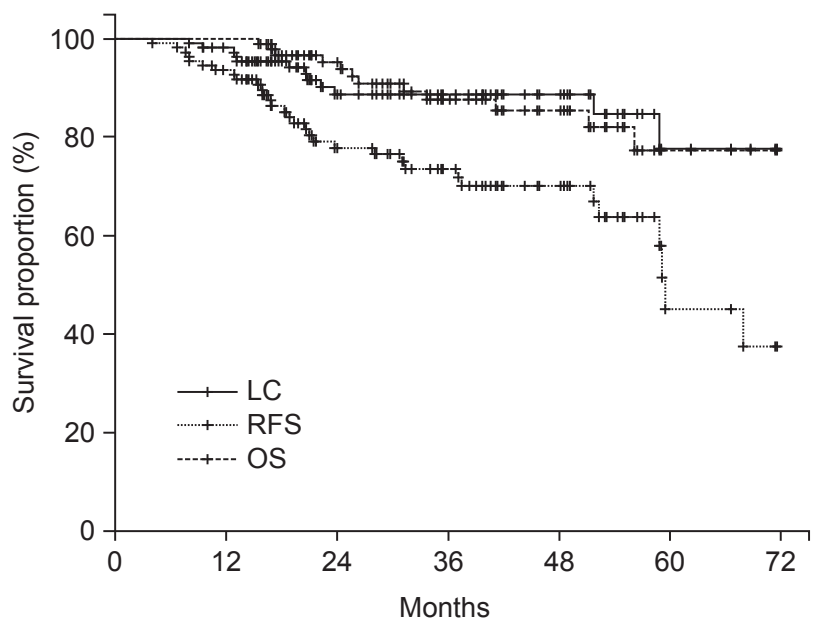

Fig. 1. Local control (LC), recurrence-free survival (RFS), and overall survival (OS).
Table 3. Prognostic factors for local control on univariate analysis

\begin{tabular}{|c|c|c|c|}
\hline Characteristic & No. & 3-yr local control & p-value \\
\hline Age (yr) & & & 0.763 \\
\hline$\leq 50$ & 16 & 92.3 & \\
\hline$>50$ & 95 & 88.3 & \\
\hline Sex & & & 0.296 \\
\hline Male & 74 & 89.7 & \\
\hline Female & 37 & 86.9 & \\
\hline BMI $\left(\mathrm{kg} / \mathrm{m}^{2}\right)$ & & & 0.045 \\
\hline$<25$ & 86 & 92.4 & \\
\hline$\geq 25$ & 25 & 76.2 & \\
\hline Diabetes & & & 0.683 \\
\hline Yes & 16 & 90.9 & \\
\hline No & 95 & 88.5 & \\
\hline CEA (ng/mL) & & & 0.349 \\
\hline$<4.7$ & 66 & 92.9 & \\
\hline$\geq 4.7$ & 45 & 82.3 & \\
\hline Clinical N stage & & & 0.574 \\
\hline No & 32 & 92.6 & \\
\hline $\mathrm{N}+$ & 79 & 87.3 & \\
\hline Type of surgery & & & 0.313 \\
\hline APR & 27 & 82.8 & \\
\hline LAR & 84 & 90.9 & \\
\hline Resection margin & & & 0.872 \\
\hline Ro & 102 & 88.7 & \\
\hline $\mathrm{R} 1-2$ & 9 & 100 & \\
\hline Type of RT & & & 0.620 \\
\hline Preoperative RT & 58 & 87.8 & \\
\hline Postoperative RT & 53 & 89.5 & \\
\hline 5-FU chemotherapy & & & 0.737 \\
\hline Yes & 75 & 89.0 & \\
\hline No & 36 & 87.9 & \\
\hline
\end{tabular}

BMI, body mass index; CEA, carcinoembryonic antigen; APR, abdominoperineal resection; $L A R$, lower anterior resection; $R T$, radiotherapy; 5-FU, 5-fluorouracil.

experienced both regional failure and distant metastases. Among them, 2 patients experienced local failure, regional lymph node failure, and distant metastases.

Fig. 1 shows patient LC rate. The 3 -year LC was $88.7 \%$. Table 3 shows prognostic factors for LC. LC was not affected by $\operatorname{sex}(p=0.296)$ or the presence of DM $(p=0.683)$. LC was not affected by age (age $>50$ years or age $\leq 50$ years, $p=0.763$ ). CEA level also did not affect the LC (CEA $\geq 4.7 \mathrm{ng} / \mathrm{mL}$ or CEA $<4.7 \mathrm{ng} / \mathrm{mL}, \mathrm{p}=0.349$ ). However, reduced LC was observed in obese patients $(p=0.045)$. Fig. 2 show the $L C$ rate according to obesity and $\mathrm{BMI}$, respectively. Among the 25 patients with obesity, 5 patients (20.0\%) experienced local failure. The 3-year LC rates were $76.2 \%$ and $92.4 \%$ for obese patients $(n=25)$ and non-obese patients $(n=86)$, respectively. Multivariate 

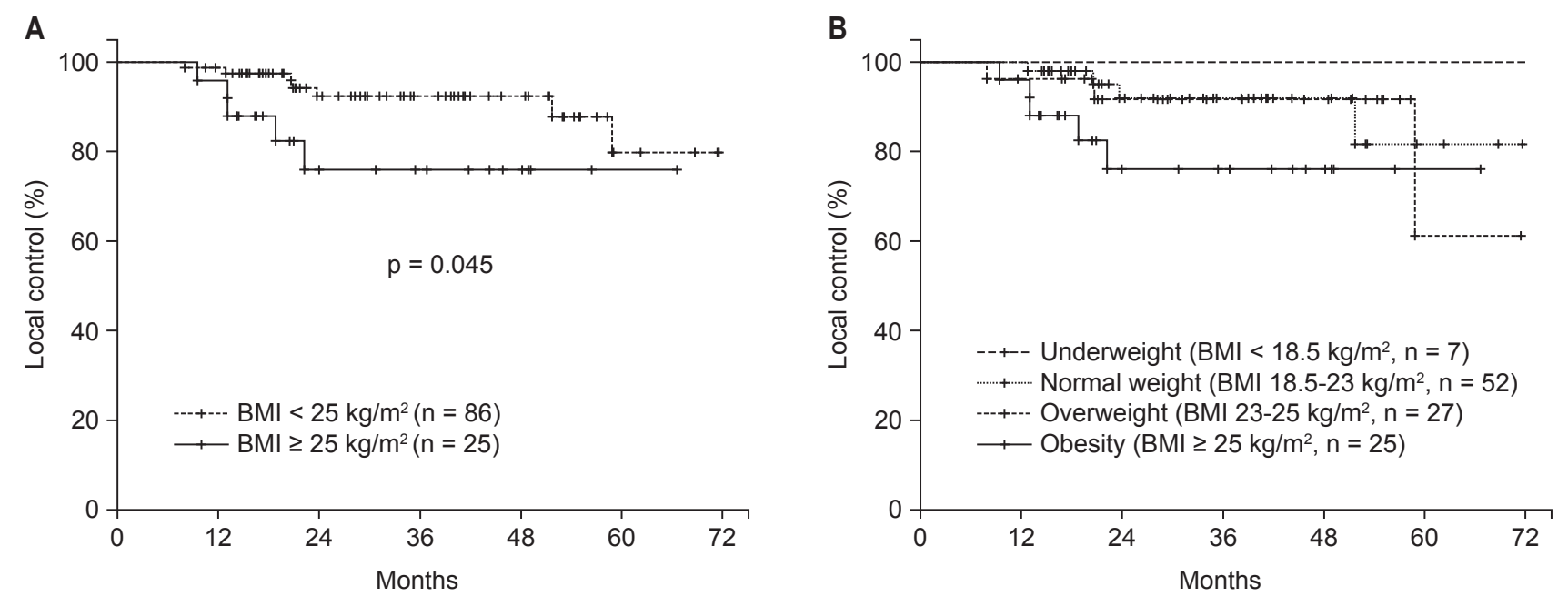

Fig. 2. Local control by (A) obesity and (B) body mass index (BMI); underweight (BMI $\left.<18.5 \mathrm{~kg} / \mathrm{m}^{2}\right)$, normal weight (BMl $\left.18.5-23 \mathrm{~kg} / \mathrm{m}^{2}\right)$, overweight (BMI $\left.23-25 \mathrm{~kg} / \mathrm{m}^{2}\right)$, and obesity $\left(B M I \geq 25 \mathrm{~kg} / \mathrm{m}^{2}\right)$.
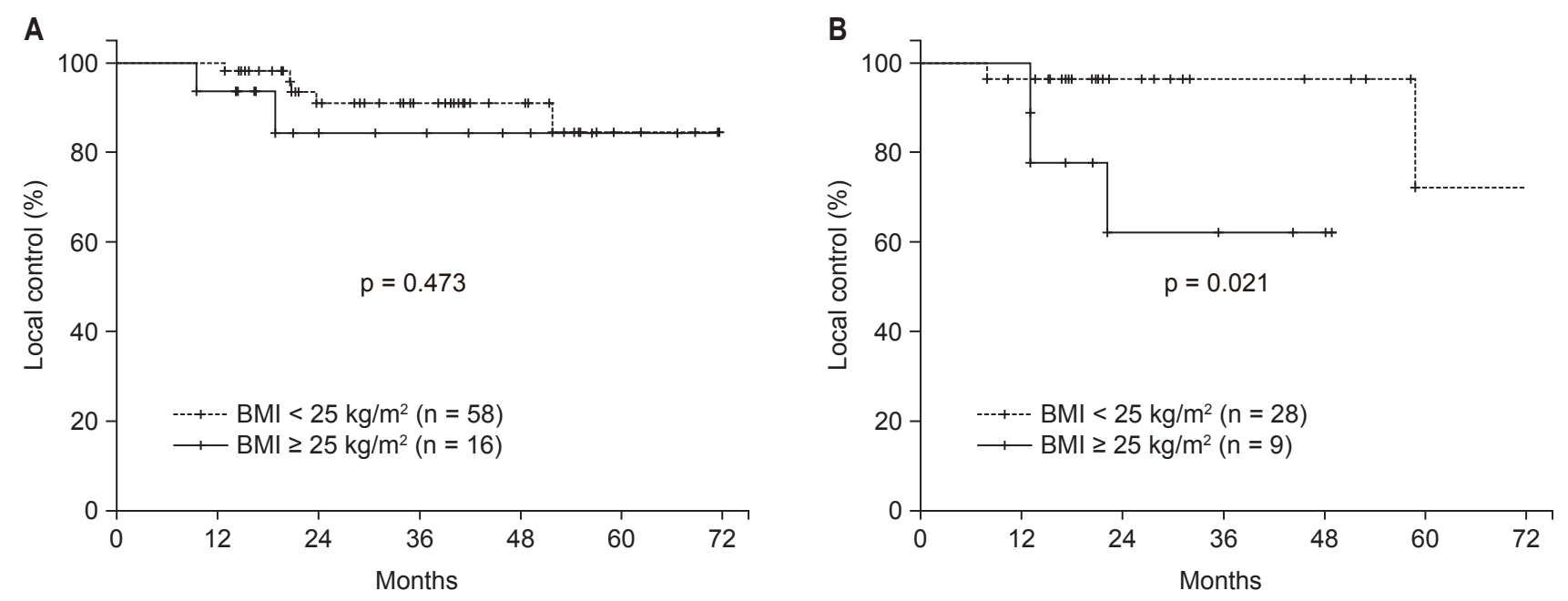

Fig. 3. Local control by obesity in (A) male patients and (B) female patients.

analysis identified obesity as an independent prognostic factor of LC (hazard ratio [HR], 3.542; $p=0.039$ ) (Table 4).

The maximal chi-square method found that segregation of LC was best achieved by BMI of $25.6 \mathrm{~kg} / \mathrm{m}^{2}$ as a cutoff value (M $=2.9672, p=0.06309$ ).

In the subgroup analysis performed according to sex, $\mathrm{LC}$ rates were not significantly affected by obesity in male patients ( $n=74, p=0.473$ ) (Fig. 3A). However, LC was significantly reduced in obese compared to non-obese female patients ( $n=37, p=0.021$ ) (Fig. 3B). In the further subgroup analysis performed according to age, old age ( $>50$ years) did not affect the LC ( $p=0.204 ; 3$-year LC for patients $>50$ years, $88 \%$ vs. age $\leq 50$ years, $100 \%)$ in male patients $(n=74)$. Also,
Table 4. Prognostic factors for local control on multivariate analysis

\begin{tabular}{lcc}
\hline \multicolumn{1}{c}{ Characteristic } & HR $(95 \% \mathrm{Cl})$ & p-value \\
\hline $\begin{array}{l}\text { Obesity }\left(\mathrm{BMI}, \mathrm{kg} / \mathrm{m}^{2}\right) \\
\quad<25 \text { vs. } \geq 25\end{array}$ & $3.542(1.065-11.778)$ & 0.039 \\
$\begin{array}{l}\text { Clinical N stage } \\
\quad \text { N0 vs. N+ }\end{array}$ & $1.460(0.388-5.502)$ & 0.663 \\
Resection margin & & \\
$\quad$ R0 vs. $\mathrm{R} 1-2$ & $2.149(0.660-6.999)$ & 0.204 \\
CEA $(\mathrm{ng} / \mathrm{mL})$ & & \\
$\quad<4.7$ vs. $\geq 4.7$ & $1.344(0.356-5.079)$ & 0.663 \\
\hline
\end{tabular}

$\mathrm{HR}$, hazard ratio; $\mathrm{Cl}$, confidence interval; $\mathrm{BMI}$, body mass index; CEA, carcinoembryonic antigen. 
old women ( $>50$ years) did not show lower LC compared to young women $(p=0.336$; 3 -year LC for patients $>50$ years, $89.8 \%$ vs. age $\leq 50$ years, $80 \%$ ) In female patients ( $n=37$ ).

The 3-year RFS and OS rates were $73.6 \%$, and $87.7 \%$, respectively (Fig. 1), and were not affected by obesity $(p=0.916$ and $p=0.697$, respectively).

\section{Discussion and Conclusion}

Our study showed that obesity is a critical prognostic factor for LC in rectal cancer. The strategy of improving LC in these patients could bring about a better outcome.

Obesity affects not only surgical complications but also treatment outcomes in rectal cancer patients [19]. Clark et al. [20] reported that elevated visceral adiposity was associated with an increased risk of recurrence after neoadjuvant chemoradiation in rectal cancer. Our results bolster this view. For local treatment, sufficient resection of the tumor might be difficult in obese patients because of limited surgical visibility. In addition, increased set-up uncertainty during RT in obese patients might influence the treatment results. Personalized $R T$ may improve the $L C$ rate in obese patients. An increase in the boost dose of RT in obese rectal cancer patients should be considered to reduce local failure. Intensive systemic treatment and active secondary prevention can also reduce the risk of local recurrence in obese patients. Intensified combination chemotherapy may reduce the overall failure rate in obese patients. Close monitoring in follow-up periods could aid early detection of local recurrence and eventually result in an improved treatment outcome. Lifestyle modification and weight control have been shown to improve outcomes in rectal cancer patients [21]. Use of statins for patients who are overweight can also be considered as a treatment strategy [22].

High-calorie Western diets and low levels of physical activity have been associated with a higher prevalence of obesity. Liu and Huang [2] reported that lipids directly or indirectly activate growth promoting signals such as those involving Iysophosphatidic acid, insulin, insulin-like growth factor (IGF)-1, and vascular endothelial growth factor to promote cancer cell growth. Obese persons develop insulin resistance with increased circulating levels of insulin, leading to higher circulating concentrations of IGF-1 [15]. This growth factor appears to stimulate proliferation of the intestinal mucosa [15]. Inflammatory cytokines from adipose cells are able to promote cancer proliferation [4]. Also, reduced sensitivity to antiangiogenic regimens can explain the worse cancer outcome in obesity. In addition, the PI3K/Akt/mTOR pathway, which is known to be related to both rectal cancer occurrence and lipid metabolism, is closely connected with the IGF-1 pathway [23]. Activation of the PI3K/Akt pathway promotes glucose uptake and its use in lipid synthesis in cancer patients [4]. A recent increase in colorectal cancer prevalence in East Asians [24] may be related to an increase in obesity caused by lifestyle or diet habit changes, which could be explained by these mechanisms. The lower $L C$ rate seen in obese patients in our study could also be explained by these lipid-related tumorigenesis mechanisms. Moreover, targeting glycolysis by Akt pathway can eliminate the chemotherapy resistance [25]. Also, Schuurbiers et al. [26] reported that the PI3K/Akt pathway was related with radiation resistance mechanisms, including radio-sensitivity, hypoxia, and cancer cell proliferation.

Within the framework of LC, women were more affected by obesity compared to men in the present study. There are several possible reasons for this result. Estrogen level might affect the risk of rectal cancer relapse in women. In addition, women are generally less exposed to other environmental risk factors such as tobacco or alcohol compared to men. Therefore, the effect of obesity on recurrence might be stronger than other factors. The mechanism behind sex differences affecting the prognostic effect of obesity on LC in rectal cancer patients should be further evaluated.

Known prognostic factors, such as resection margin status, CEA level, and lymph node involvement, did not show significant prognostic effects on LC in this study. There are several possible reasons for these results. First, the adverse effect of positive resection margin was offset by RT. Second, all rectal cancer patients who underwent RT were composed of advanced-stage cancer patients. Therefore, the adverse effect of lymph node positivity was not seen this study. Finally, the relatively small sample size of this study might have obscured the statistical differences.

DM is a well-known risk factor for recurrence in colorectal cancer [27]. The negative effect of DM on rectal cancer patients' survival was recently revealed [28]. Moreover, obesity is a well-known predisposing factor for type $2 \mathrm{DM}$. Even though our study failed to show the relationship between DM and rectal cancer local recurrence, this result may be affected by the relatively small number of patients in this study. Further large-scale of studies may confirm the effect of DM in rectal cancer local recurrence.

A limitation of this study is that we were unable to fully evaluate the effect of the dose, regimen, and number of cycles of chemotherapy on LC owing to lack of complete medical records. Thus, we cannot rule out that the obese patients might 
have been treated with inadequate doses of chemotherapy, which could affect LC. In regard to surgical management, obesity might increase operating time and conversion rates to operation [19]. In addition, selection bias should be taken into consideration because of the retrospective design of this study. Moreover, the prognostic effect of obesity on rectal cancer should be interpreted carefully, because of the relatively small sample size of this study.

In conclusion, obese rectal cancer patients have a lower rate of LC after combined surgery and RT compared to normal weight patients. Therefore, a more effective treatment strategy to improve LC for patients with obesity is warranted.

\section{Conflict of Interest}

No potential conflict of interest relevant to this article was reported.

\section{References}

1. Seyfried TN, Flores RE, Poff AM, D'Agostino DP. Cancer as a metabolic disease: implications for novel therapeutics. Carcinogenesis 2014;35:515-27.

2. Liu R, Huang Y. Lipid signaling in tumorigenesis. Mol Cell Pharmacol 2014;6:1-9.

3. Singla P, Bardoloi A, Parkash AA. Metabolic effects of obesity: a review. World J Diabetes 2010;1:76-88.

4. Santos CR, Schulze A. Lipid metabolism in cancer. FEBS J 2012;279:2610-23.

5. Renehan AG, Tyson M, Egger M, Heller RF, Zwahlen M. Bodymass index and incidence of cancer: a systematic review and meta-analysis of prospective observational studies. Lancet 2008;371:569-78.

6. Parr CL, Batty GD, Lam TH, et al. Body-mass index and cancer mortality in the Asia-Pacific Cohort Studies Collaboration: pooled analyses of 424,519 participants. Lancet Oncol 2010;11:741-52.

7. Calle EE, Rodriguez C, Walker-Thurmond K, Thun MJ. Overweight, obesity, and mortality from cancer in a prospectively studied cohort of U.S. adults. N Engl J Med 2003;348:1625-38.

8. Ma $Y$, Yang $Y$, Wang $F$, et al. Obesity and risk of colorectal cancer: a systematic review of prospective studies. PLoS One 2013;8:e53916.

9. Moghaddam AA, Woodward M, Huxley R. Obesity and risk of colorectal cancer: a meta-analysis of 31 studies with 70,000 events. Cancer Epidemiol Biomarkers Prev 2007;16:2533-47.

10. Keum N, Greenwood DC, Lee DH, et al. Adult weight gain and adiposity-related cancers: a dose-response meta-analysis of prospective observational studies. J Natl Cancer Inst 2015;107:djv088.

11. Keimling $M$, Renehan AG, Behrens $G$, et al. Comparison of associations of body mass index, abdominal adiposity, and risk of colorectal cancer in a large prospective cohort study. Cancer Epidemiol Biomarkers Prev 2013;22:1383-94.

12. Aleksandrova K, Nimptsch $K_{1}$ Pischon T. Obesity and colorectal cancer. Front Biosci (Elite Ed) 2013;5:61-77.

13. Glimelius B, Tiret E, Cervantes A, Arnold D; ESMO Guidelines Working Group. Rectal cancer: ESMO Clinical Practice Guidelines for diagnosis, treatment and follow-up. Ann Oncol 2013;24 Suppl 6:vi81-8.

14. Peeters KC, Marijnen CA, Nagtegaal ID, et al. The TME trial after a median follow-up of 6 years: increased local control but no survival benefit in irradiated patients with resectable rectal carcinoma. Ann Surg 2007;246:693-701.

15. Kasper DL, Fauci AS, Hauser SL, Longo DL, Jameson JL, Loscalzo J. Harrison's principles of internal medicine. 19th ed. New York, NY: McGraw Hill Education; 2015.

16. Seishima R, Okabayashi $K$, Hasegawa $H$, et al. Obesity was associated with a decreased postoperative recurrence of rectal cancer in a Japanese population. Surg Today 2014;44:2324-31.

17. Park IJ, You YN, Skibber JM, et al. Oncologic and functional hazards of obesity among patients with locally advanced rectal cancer following neoadjuvant chemoradiation therapy. Am J Clin Oncol 2016 Mar 29 [Epub]. http://dx.doi.org/10.1097/ C0C.0000000000000150.

18. WHO Expert Consultation. Appropriate body-mass index for Asian populations and its implications for policy and intervention strategies. Lancet 2004;363:157-63.

19. Whitlock K, Gill RS, Birch DW, Karmali S. The association between obesity and colorectal cancer. Gastroenterol Res Pract 2012;2012:768247.

20. Clark W, Siegel EM, Chen YA, et al. Quantitative measures of visceral adiposity and body mass index in predicting rectal cancer outcomes after neoadjuvant chemoradiation. J Am Coll Surg 2013;216:1070-81.

21. Tarraga Lopez PJ, Albero JS, Rodriguez-Montes JA. Primary and secondary prevention of colorectal cancer. Clin Med Insights Gastroenterol 2014;7:33-46.

22. Chan KK, Oza AM, Siu LL. The statins as anticancer agents. Clin Cancer Res 2003;9:10-9.

23. Wang XW, Zhang YJ. Targeting mTOR network in colorectal cancer therapy. World J Gastroenterol 2014;20:4178-88.

24. Jung KW, Won YJ, Kong HJ, et al. Cancer statistics in Korea: incidence, mortality, survival, and prevalence in 2012. Cancer Res Treat 2015;47:127-41.

25. Liu PP, Liao J, Tang ZJ, et al. Metabolic regulation of cancer cell side population by glucose through activation of the Akt pathway. Cell Death Differ 2014;21:124-35.

26. Schuurbiers OC, Kaanders JH, van der Heijden HF, Dekhuijzen 
RP, Oyen WJ, Bussink J. The PI3-K/AKT-pathway and radiation resistance mechanisms in non-small cell lung cancer. J Thorac Oncol 2009;4:761-7.

27. Stein KB, Snyder CF, Barone BB, et al. Colorectal cancer outcomes, recurrence, and complications in persons with and without diabetes mellitus: a systematic review and metaanalysis. Dig Dis Sci 2010;55:1839-51.

28. Huang YC, Lin JK, Chen WS, et al. Diabetes mellitus negatively impacts survival of patients with colon cancer, particularly in stage II disease. J Cancer Res Clin Oncol 2011;137:211-20. 